Dhaka Univ. J. Biol. Sci. 31(1): 19-27, 2022 (January) DOI: https://doi.org/10.3329/dujbs.v31i1.57913

\title{
IMPACTS OF WATER QUALITY ON FINFISH AND SHELLFISH BIODIVERSITY IN THE RIVER MEGHNA
}

\author{
MM ISLAM ${ }^{1}$, A HoSSAIN AND SC MANDAL* \\ Department of Fisheries, University of Dhaka, Dhaka 1000, Bangladesh
}

Key words: Water quality, Fish diversity, Species richness, Shannon-Wiener indices

\begin{abstract}
Fish biodiversity largely depends on different environmental factors including water quality parameters. The current study was conducted to investigate the impacts of water quality variables on fish biodiversity at upstream and downstream of the river Meghna in dry and rainy season in 2011. Twelve water samples and 66 fish samples were collected from 2 different sampling stations of the river Meghna during the study period where 61 were finfish species and 5 were shellfish species. The number of finfish and shellfish catch at upstream in both dry and rainy seasons were significantly higher than that of downstream $(\mathrm{p}<0.01)$. Shannon-Weiner index and species richness were determined where significantly higher Shannon-Weiner index was observed at upstream in dry season than that of downstream $(\mathrm{p}<0.01)$ and similar species richness was observed at upstream and downstream in both of the seasons. Significant correlation was observed between physicochemical parameters and the fish biodiversity indices. The obtained results suggested that the changes in environmental parameters of water including conductivity, pH, DO, BOD had significant impacts on Shannon-Wiener indices at downstream which indicate the water quality detarioration. This findings have the implications in designing polices to sustain the finfish and shellfish biodiversity and to mitigate the environmental changes in the river Meghna.
\end{abstract}

\section{Introduction}

Bangladesh is blessed with extensive water resources including ponds, lakes, rivers, canals, estuaries and sea which together account water area of 4.73 million hectares ${ }^{(1)}$. These enormous areas have enriched fisheries sector of the country. The economy and socio-cultural life largely depend on fisheries sector. Open water capture fisheries specially riverine and estuarine systems conjointly have contributed $7.5 \%$ of total fish production in 2017-2018 to the fisheries sector of Bangladesh. The landmass comprises mainly the delta of the three major rivers: the Ganges, the Brahmaputra and the Meghna. There are also thousands of tributaries with a total length of about $24,140 \mathrm{~km}$. The Meghna is one of the biggest rivers of the country which has it's great estuary that discharges the flows of the Ganges-Padma, the Brahmaputra-Jamuna and the Meghna itself. The current deltaic Meghna together with Padma and Meghna, forms the the largest river of Bangladesh.

These rivers are the sources of many aquatic resources where fishes are the principal output. According to the Red List of Bangladesh, 64 freshwater fish species are threatened in Bangladesh

*Author for correspondence: <shankar@du.ac.bd>. ${ }^{1}$ Present address: Upazilla Fisheries Office, Akkelpur, Joypurhat, Bangladesh. 
where 9 species are listed as critically endangered; 30 as endangered and 25 as vulnerable ${ }^{(2)}$. Considering the habitat structure of Meghna, it's downstream encounters huge industrial and urbanizing infestation along with mechanical fishing effort and fuel transportation which trigger the water quality degradation. A larger number of anthropogenic activities such as human settlements, towns, ports and industries (thermal power plant, fertilizer factories) have sprung up on both the banks of the Meghna. All of these stressors have made the downstream prone to water pollution that severely affect the aquatic diversity. These stressors directly or indirectly influence on the water chemistry thus changing the values of different physicochemical paremeters.

Physicochemical parameters reflect the abundance of freshwater fisheries biodiversity. Water temperature, $\mathrm{pH}, \mathrm{DO}, \mathrm{BOD}$, conductivity, depth and water velocity influence the water chemistry. Several studies have been conducted on the fish biodiversity and physicochemical parameters in the river Meghna ${ }^{(3-4)}$. However no comprehensive study was carried out addressing the impact of water quality degredation on finfish and shellfish richness and diversity indices at upstream and downstream. Current study was thus conducted to estimate the present status of finfish and shellfish diversity of the river Meghna and to assess the impact of some physicochemical parameters of water on the biodiversity indices.

\section{Materials and methods}

The present study was carried out at upstream (Ajmiriganj and Habiganj) and at downstream (Bhairab Bazar and Kishoreganj) of the river Meghna during dry and rainy season in 2011. The downstream of Surma river from Ajmiriganj is often referred to as the Meghna and this region was considered as the upstream in the study. The channel from Ajmiriganj down to the confluence with the Dhanu river is referred to as the Surma. The Meghna receives the old Brahmaputra on its right at Bhairab Bazar. The width of the river is three quarters of a kilometer. Several small channels branching off from the Meghna and meandering through the low land bordering the Tippera surface received the flow of a number of hilly streams and rejoin the main river downstream. Two different stations were selected each for upstream sampling and downstream sampling. In each station, 2 samplings were done where in each sampling 3 nettings were performed using cast net and seine net.

Different water quality variables were determined in samples taken from upstream and downstream of the river Meghna. $\mathrm{pH}$ was determined using Orion field $\mathrm{pH}$ meter (model 210A, Orion Laboratories) with a glass combination electrode and automatic temperature compensation probe calibrating with buffers at $\mathrm{pH} 4.7$ and 10.0 at $25^{\circ} \mathrm{C}$. Electrical conductivity was determined using conductivity meter (HACH, Model CO150). Dissolved oxygen was measured using a portable DO meter (HACH, Model DO175). Biochemical oxygen demand (BOD), total dissolved solids (TDS), turbidity, total nitrogen (TN) and free ammonia $\left(\mathrm{NH}_{3}\right)(\mathrm{FA})$ content of water were determined according to APHA ${ }^{(5)}$. Water samples were analyzed in the Department of Soil, Water and Environment, University of Dhaka and Department of Fisheries, University of Dhaka. Eight major water quality parameters which have influence on fish biodiversity (BOD, DO, pH, TDS, 
turbidity, electrical conductivity, total nitrogen and free ammonia were taken under consideration to determine the Water Quality Index (WQI) as explained in Water Research Center by Oram ${ }^{(6)}$.

For the determination of diversity indices total samples of fish in each sampling were recorded from 12 nettings using cast net and seine net from the sampling stations (one at upstream and one at downstream) during the study period. Fishes and shellfishes were identified up to species level by following Shafi and Quddus ${ }^{(7)}$. Species richness, total individual counts in a sample and also, total number of individuals under each species were estimated. Shannon-Wiener index (SWI) values were calculated by Maryland computer online calculation for biodiversity ${ }^{(8)}$. Both number of species and their abundance/density are considered in Shannon-Weiner diversity index ${ }^{(9-10)}$. Shannon-Wiener indices (SWI) obtained from the fish samples were considered as the dependent variables where as the values of 8 parameters of water were considered as the independent variables. Data were analysed using SPSS (Statistical Package for Social Science) version 20 and Microsoft Excel 2016. Pearson correlation test was performed to determine the correlations between the variables with the level of significance at $p<0.05$. Regression analysis between diversity index and water quality variables was also performed. Principal component analysis (PCA) was done to determine the key factors correlated with SWI and species richness. Data were transformed to natural logarithm before conducting PCA.

\section{Results and Discussion}

Variation in water quality parameters: Total Nitrogen (TN) concentration determined in water sampled from downstream of the river Meghna was higher than that of upstream during the dry season (Table 1). Lowest TN value (around $0.66 \mathrm{mg} / \mathrm{l}$ ) was recorded from upstream during rainy season. Dissolved oxygen (DO) at upstream was lower than downstream in both dry and rainy seasons. Average DO concentration at upstream was higher than downstream. Overall DO values recorded during the study period ranged between 6 and $7.5 \mathrm{mg} / \mathrm{l}$ which were favourable for fishes ${ }^{(11)}$. Significantly higher BOD was observed at downstream $(\mathrm{p}<0.0001)$. Indiviadually, both dry and rainy season at downstream showed significantly higher BOD than that of upstream $(p<0.01)$. Similarly, significantly higher concentration of TDS and EC were found at downstream in both seasons than that of upstream $(\mathrm{p}<0.01)$. Higher but not significant turbidity was observed during rainy season at both upstream and downstream. Average free ammonia (FA) concentration was similar in both upstream and downstram (Table 1).

Species diversity: A total number of 61 finfish and 5 shellfish species were recorded from upstream and downstream of the river Meghna. In the present study, 42 species of finfish and 5 species of shellfish were observed in the upstream while in the downstream 34 species of finfish and 5 species of shellfish were found (Table $2 \mathrm{a}$ and $2 \mathrm{~b}$ ). Among the finfish, 27 species were found only in the upstream and 19 only in the downstream (Table 2a). All 5 species of shellfish were found in both upstream and downstream (Table 2b). 
Table 1. Water quality variables (Mean \pm Standard Error of Mean) of water samples $(n=3)$.

\begin{tabular}{lcccc}
\hline Water quality & \multicolumn{2}{c}{ Upstream } & \multicolumn{2}{c}{ Downstream } \\
\cline { 2 - 5 } variables & Dry season & Rainy season & Dry season & Rainy season \\
\hline $\mathrm{pH}$ & $6.87 \pm 0.32$ & $6.25 \pm 0.27$ & $7.01 \pm 0.25$ & $7.06 \pm 0.49$ \\
$\mathrm{DO}(\mathrm{mg} / \mathrm{l})^{*}$ & $6.33 \pm 0.54$ & $6.66 \pm 0.71$ & $5.45 \pm 0.33$ & $5.00 \pm 0.50$ \\
$\mathrm{BOD}(\mathrm{mg} / \mathrm{l})^{* * *}$ & $2.96 \pm 0.19$ & $3.09 \pm 0.34$ & $4.37 \pm 0.33^{*}$ & $4.55 \pm 0.26^{*}$ \\
$\mathrm{TDS}(\mathrm{mg} / \mathrm{l})^{* *}$ & $28.63 \pm 1.68$ & $28.43 \pm 3.04$ & $36.00 \pm 1.30^{*}$ & $38.63 \pm 0.67^{*}$ \\
$\mathrm{EC}(\mu \mathrm{S} / \mathrm{cm})^{* *}$ & $70.23 \pm 5.43$ & $72.47 \pm 3.71$ & $89.87 \pm 4.81^{*}$ & $93.27 \pm 1.65^{*}$ \\
Turbidity $(\mathrm{FTU})$ & $36.78 \pm 19.63$ & $64.35 \pm 24.58$ & $54.69 \pm 22.62$ & $64.35 \pm 19.09$ \\
Total Nitrogen $(\mathrm{mg} / \mathrm{l})^{*}$ & $0.71 \pm 0.10$ & $0.66 \pm 0.06$ & $1.04 \pm 0.03^{*}$ & $0.89 \pm 0.08$ \\
Free ammonia $(\mathrm{mg} / \mathrm{l})$ & $3.57 \pm 1.60 \times 10^{-4}$ & $4.90 \pm 1.57 \times 10^{-4}$ & $5.47 \pm 1.36 \times 10^{-4}$ & $4.00 \pm 0.62 \times 10^{-4}$
\end{tabular}

Asterisk at the variable name indicates significantly different between overall values of upstream and downstream. Asterisk at other values are significantly different within season between upstream and downstream (*, $* *$ and $* * *$ denote significantly different at $\mathrm{p}<0.01, \mathrm{p}<0.001$ and $\mathrm{p}<0.0001$, respectively).

Table 2a. Finfish species found at upstream and downstram of the river Meghna.

\begin{tabular}{lllll}
\hline $\begin{array}{l}\text { Sl. } \\
\text { No. }\end{array}$ & Order & Family & Scientific Name & Location of \\
availability
\end{tabular}




\begin{tabular}{|c|c|c|c|c|}
\hline $\begin{array}{l}\text { Sl. } \\
\text { No. }\end{array}$ & Order & Family & Scientific Name & $\begin{array}{l}\text { Location of } \\
\text { availability }\end{array}$ \\
\hline 29 & & & Channa punctatus & Upstream \\
\hline 30 & & & Channa striatus & Both \\
\hline 31 & Perciformes & Anabantidae & Anabas testudineus & Upstream \\
\hline 32 & & & Nandus nandus & Upstream \\
\hline 33 & & Ambassidae & Chanda nama & Upstream \\
\hline 34 & & & Parambassis ranga & Downstream \\
\hline 35 & & Badidae & Badis badis & Downstream \\
\hline 36 & & Gobiidae & Glossogobius giuris & Both \\
\hline 37 & & Nandidae & Nandus nandus & Downstream \\
\hline 38 & & Sciaenidae & Pama pama & Both \\
\hline 39 & & Osphronemidae & Trichogaster fasciata & Both \\
\hline 40 & Siluriformes & Schilbeidae & Ailia coila & Both \\
\hline 41 & & & Ailia punctata & Downstream \\
\hline 42 & & Clariidae & Clarias batrachus & Upstream \\
\hline 43 & & Schilbeidae & Clupisoma garua & Upstream \\
\hline 44 & & & Eutropiichthys vacha & Upstream \\
\hline 45 & & & Neotropius atherinoides & Upstream \\
\hline 46 & & Sisoridae & Gagata gagata & Upstream \\
\hline 47 & & & Bagarius bagarius & Downstream \\
\hline 48 & & Heteropneustidae & Heteropneustes fossilis & Upstream \\
\hline 49 & & Bagridae & Mystus aor & Both \\
\hline 50 & & & Mystus tengara & Upstream \\
\hline 51 & & & Mystus cavasius & Downstream \\
\hline 52 & & & Mystus bleekeri & Downstream \\
\hline 53 & & & Mystus vittatus & Both \\
\hline 54 & & Siluridae & Ompok bimaculatus & Upstream \\
\hline 55 & & & Ompok pabda & Both \\
\hline 56 & & & Wallago attu & Upstream \\
\hline 57 & Synbranchiformes & Mastacembelidae & Macrognathus aculeatus & Upstream \\
\hline 58 & & & Macrognathus aral & Upstream \\
\hline 59 & & & Mastacembelus armatus & Upstream \\
\hline 60 & & & Mastacembelus pancalus & Upstream \\
\hline 61 & & Synbranchidae & Monopterus cuchia & Upstream \\
\hline
\end{tabular}

Table 2b. Shellfish species found in both upstream and downstram of the river Meghna.

\begin{tabular}{llllll}
\hline $\begin{array}{l}\text { Sl. } \\
\text { No. }\end{array}$ & Phylum & Class & Order & Family & Scientific name \\
\hline 1 & Arthropoda & Malacostraca & Decapoda & Palaemonidae & $\begin{array}{l}\text { Leander stylifera } \\
\text { Macrobrachium malcolmsonii }\end{array}$ \\
3 & & & & & $\begin{array}{l}\text { Macrobrachium rosenbergii } \\
4\end{array}$ \\
5 & & & & & $\begin{array}{l}\text { Macrobrachium rudis } \\
\text { Scylla serrata }\end{array}$ \\
\hline
\end{tabular}

Species diversity index and water quality variables: Finfish and shellfish diversity at upstream and downstream of the river Meghna was determined by the catch of nettings where the total number of catch in dry season at upstream was significantly higher than that of downstream $(p<0.01$, Table 3). Number of species were at upstream was higher than downstream but not significant. SWI and richness were determined where SWI in dry season at upstream was 
significantly higher than that of downstream $(\mathrm{p}<0.01)$. Similar species richness was observed in both seasons at both sampling stations (Table 3).

Shannon-Wiener index (SWI) was negatively correlated with at both study areas. Similar results were observed by Bashir et al., 2010 ${ }^{(12)}$. Negative correlations were found with BOD and turbidity at upstream levels whereas with DO and FA at the downstream levels. Positive correlations were observed with BOD, EC, TDS and turbidity at the downstream level while it observed with EC, DO, TDS and FA at upstream areas (Table 4). Regression coefficient (B) of Shannon-Wiener index (SWI) were less on $\mathrm{pH}$ and $\mathrm{TN}$ at both sampling areas whereas the coefficient $(\mathrm{B}=-0.6678)$ of SWI on BOD at upstream and the coefficient $(\mathrm{B}=-0.561)$ on FA at downstream were the least in values. On the other hand, the coefficient $(B=0.143)$ of SWI on FA at upstream was positive. The other coefficients of SWI on BOD at downstream; on DO at upstream; on TDS, EC and turbidity at the both sampling areas were positive in values (regression graphs not shown).

Table 3. Finfish and shellfish species diversity during the study period at upstream and downstream during dry and rainy season.

\begin{tabular}{lcccc}
\hline Indicators & \multicolumn{2}{c}{ Upstream } & \multicolumn{2}{c}{ Downstream } \\
\cline { 2 - 5 } & Dry season & Rainy season & Dry season & Rainy season \\
\hline SWI & $2.35 \pm 0.13^{*}$ & $2.04 \pm 0.22$ & $1.72 \pm 0.05$ & $2.06 \pm 0.14$ \\
Species richness & $14.67 \pm 1.20$ & $12.00 \pm 3.61$ & $8.00 \pm 0.58$ & $10.00 \pm 1.00$ \\
$\begin{array}{l}\text { Number of fish and shellfish } \\
\text { species caught }\end{array}$ & 36 & 32 & 21 & 27 \\
Total catch (number) & $158^{*}$ & 115 & 83 & 98 \\
\hline
\end{tabular}

Three nettings were performed for each season at both upstream and downstream to catch the fish and shellfish. Asterisk $(*)$ indicates significantly different at $\mathrm{p}<0.01$.

Table 4. Correlation matrix between Shannon-Wiener Index and independent variables (Water quality parameters). Values are Pearson correlation coefficients, $\mathbf{p}<0.01$.

\begin{tabular}{lcccccccc}
\hline & & \multicolumn{7}{c}{ Water quality parameters } \\
\hline & $\mathrm{pH}$ & $\mathrm{BOD}$ & $\mathrm{EC}$ & $\mathrm{TN}$ & $\mathrm{DO}$ & TDS & Turbidity & FA \\
\hline Up stream & -0.219 & -0.678 & 0.373 & -0.910 & 0.050 & 0.491 & -.019 & 0.143 \\
Down stream & -0.808 & 0.416 & 0.190 & -0.524 & -0.689 & 0.528 & 0.370 & -0.561 \\
\hline
\end{tabular}

Principal component analysis (PCA): A PCA was performed to establish relationship between the variables. Varimax rotation was performed to reduce the variable and simplify the interpretation of different variables. Varimax grouped the variable into fewer factors, thus simplified the interpretation. The rotation mode reduced all variables into two factors, which represented 68.3 and $70.1 \%$ of the cumulative variances respectively for Shannon-Wiener Index (SWI) and water quality variables; and species richness and water quality variables. In case of diversity index, SWI was negatively correlated with TDS, EC and BOD (PC1); and BOD, pH, TDS, EC, BOD and TN were positively correlated (PC2) while no correlation was found with 
turbidity and FA (Fig. 1A). Similar trend was found for species richness and other variables (Fig. 1B).

(A)

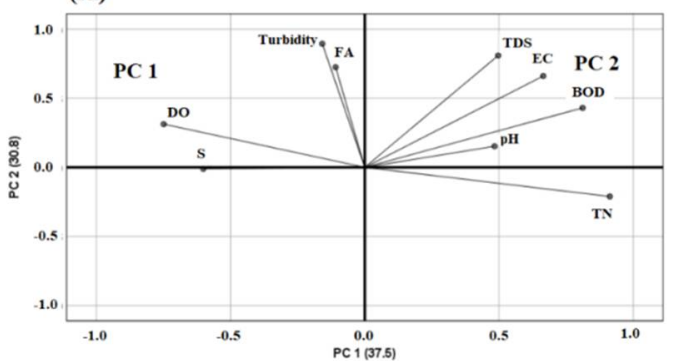

(B)

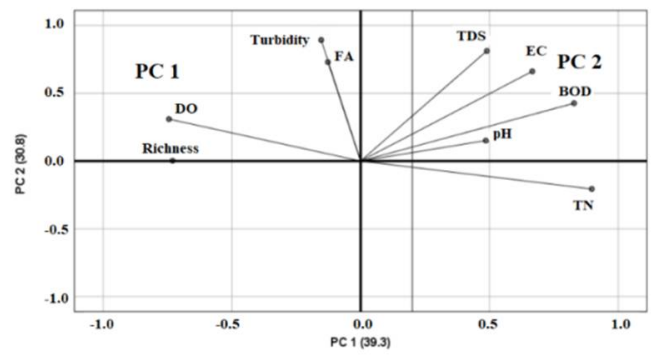

Fig. 1. Principal component analysis (PCA) between SWI and water quality variables (A); and richness and water quality variables (B).

Different fish species composition has been reported by several authors for a different section of Bangladesh ${ }^{(13)}$. Very limited research works have been conducted on the fish biodiversity of Meghna River. An account of 293 freshwater fish species including 13 orders and 61 families was reported in different water bodies including river, haor, baors, streams, floodplains, beels and lakes in Bangladesh ${ }^{(14)}$. In another study a list of 265 species of freshwater fishes belonging to 154 genera and 55 families from Bangladesh have been reported ${ }^{(15)}$. Fish species recorded in the study comprehensively suggests that the river Meghna is an incredible resource of inland fishes at the upstream level whereas at the downstream level fish species diversity was comparatively prominent. Sixty six species of finfish (61) and shellfish (5) were found at upstream and downstream with sufficient number of individuals. Significant correlation between various physicochemical variables in the Meghna river system was observed in the current study which means physicochemical parameters are interdependent where change in one parameter might change others. Shannon-Wiener index was positively correlated with turbidity at downstream which may be due to the effects of rainy season where the turbidity is due to nutrients and primary producers. SWI was positively correlated with TDS at downstream which may be because of the higher extent of sedimentation and higher content of nutrients. Electrical conductivity (EC) is an important parameter which indirectly analyzes the rivers' quality ${ }^{(16-17)}$. Previously, the highest value $(220 \mu \mathrm{S} / \mathrm{cm})$ of conductivity was recorded at downstream level of Meghna. Southern Regional Aquaculture Centre (SRAC) ${ }^{(18)}$ demonstrated that the optimum EC for fish culture should be between 60 and $2000 \mu \mathrm{S} / \mathrm{cm}$. The EC observed in the present study was within this range. The higher level of TDS allowed the EC level to be higher as well.

Turbidity is another indicator of water quality. The recommended range of turbidity for fish culture is $30-80 \mathrm{~cm}^{(19)}$ and turbidity observed in the present study is within the range. In the upstream, turbidity was negatively correlated with fish diversity index. Seasonal variation especially the rainy season has prominent effects on turbidity. Rainy season generally affects the turbidity level of flowing water body. Besides this effect, the other effects would be the geographical and habitat structure of the Meghna where the area of floodplains were large at the 
upstream level than downstream what becomes inundated and associated with the river flow due to the uprising water level of rainy season. Chances of alluvial deposition and siltation from the floodplains probably made upstream level much siltation prone where the siltation proved to be the major source of turbidity.

DO is one of the most important water quality parameters and limiting factors. For better growth of fish, DO should be above $5 \mathrm{mg} / \mathrm{l}^{(19)}$. DO in both upstream and downstream of the river Meghna was within the optimum range. Shannon-Wiener index was also positively correlated with DO at upstream because of the increment of DO levels during rainy season. Proper extent of seasonal water mixing made the DO level much higher in that period. DO content was found to gradually decrease from the upper to lower stretches of the Meghna river system as expected for many major rivers ${ }^{(20)}$. Fish growth and survival depend on $\mathrm{pH}$ to some extent ${ }^{(21)}$. Northeastern Regional Aquaculture Centre (NRAC) recommended that for fish to survive and grow best in waters with a $\mathrm{pH}$ between 6 and $9^{(21)}$. The $\mathrm{pH}$ observed in the upstream was within the range, however, at downstream recorded $\mathrm{pH}$ was slightly lower than the lower recommended value. Correlation between SWI and total $\mathrm{NH}_{3}$ at downstream level demonstrate the higher content of nitrogen sources from the numerous industrial and mechanical effluents like Ashuganj power plant, Fenchuganj urea fertilizer factory etc.

Hossain et $_{\text {al }}{ }^{(3)}$ found 53 fish species at estuarine Meghna where in the present study similar number of fish species was observed Water quality parameters including conductivity, depth and salinity have been shown to significantly influence the fish biodiversity in Indian floodplains and lakes ${ }^{(22)}$. The richness and abundance of fishes have also been shown to be correlated with turbidity and $\mathrm{pH}$ in coastal rivers of India ${ }^{(23)}$ which supports the findings of the current study. The findings suggest that there is deliberate effects of water quality on fish diversity at downstream but in some cases index was low although the water quality was pretty good. The findings might be used in future research for predictions over temporal scales.

\section{Acknowledgements}

Authors would like to acknowledge the support and guidance of Dr. Dewan Ali Ahsan, formar Professor of the Department of Fisheries, University of Dhaka and Associate professor at Department of Sociology, Environmental and Business Economics, University of Southern Denmark. Authors would also like to thank to the Department of Soil, Water and Environment of the University of Dhaka for their support to analyse the water samples.

\section{References}

1. DoF 2018. Yearbook of Fisheries Statistics of Bangladesh, 2017-18. Fisheries Resources Survey System (FRSS), Department of Fisheries. Ministry of Fisheries, Bangladesh. 35: 129.

2. IUCN Bangladesh 2015. Red List of Bangladesh: Volume 5 Freshwater Fishes. IUCN,International Union for Conservation of Nature Bangladesh Country Office, Dhaka, Bangladesh, pp. xvi+350.

3. Hossain MS, NG Das, S Sarker and MZ Rahaman 2012. Fish diversity and habitat relationship with environmental variables at Meghna river estuary, Bangladesh. The Egyptian J. Aq. Res. 38(3): 213226. 
4. Begum S, MS Islam, M Rehnuma, MH Kabir and TR Tusher 2019. Water quality and fish diversity status in Meghna River at Narsingdi in Bangladesh. Bangladesh J. Environ. Sci. 37: 25-31.

5. APHA 1995. Standard Methods for the Examination of Water and Waste Water. 19th Edn., The American Public Health Association, Washington, DC, USA.

6. Oram B 2014. Water Research Center: Monitoring the Quality of Surface Waters (WQI Calculator). Available at: https://www.water-research.net/index.php/water-treatment/water-monitoring/monitoring-the-quality-of-surfacewaters

7. Shafi M and MMA Quddus 1982. Bangladesher Matshya Sampad (in Bangla), Bangla Academy, Dhaka.

8. Sea Grant Maryland 2021. Available at: https://www.mdsg.umd.edu/topics/k-12-lesson- plans/biofilmsand-biodiversity.

9. Shannon CE, W Weaver 1963. The Mathematical Theory of Communications. University of Illinois Press, Urbana, IL, pp. 125.

10. Ramos S, KK Cowen, $P R^{\prime}$ and AA Bordalo 2006. Temporal and spatial distribution of larval fish assemblages in the Lima estuary (Portugal). Estuarine, Coastal and Shelf Sci. 66: 30314.

11. Mallya YJ and H Thorarensen 2007. The effects of dissolved oxygen on fish growth in aquaculture. UNU-Fisheries Training Programme, 12-13.

12. Bashir T, A Khan, P Gautam and SK Behera 2010. Abundance and Prey Availability Assessment of Ganges River Dolphin (Platanista gangetica gangetica) in a Stretch of Upper Ganges River, India. Aqu. Mammals. 36: 9-26.

13. Chowdhury MSN, MS Hossain, NG Das 2010. Environmental variables and fisheries diversity of the Naaf River Estuary, Bangladesh. J. Coast. Conserv. 15: 163-180

14. Hossain MAR, AM Wahab, B Belton 2012. The Checklist of the Riverine Fishes of Bangladesh. The world Fish Center, Bangladesh and South Asia Office, Dhaka.

15. Rahman AKA 2005. Freshwater fishes of Bangladesh, second edition. Zoological Society of Bangladesh, Department of Zoology, University of Dhaka, pp. 263.

16. Braul I, J Desrosiers and M Watson 2011. An Analysis of Downstream Changes in Temperature, Electrical Conductivity and Total Dissolved Solids of the Illecillewaet River and Asulkan Brook in Glacier National Park, B.C. Geog 477 Research Report, 1-33.

17. Patel V, P Parikh 2013. Assessment of seasonal variation in water quality of River Mini,

at Sindhrot, Vadodara. Int. J. Environ. Sci. 3(5): 1425-1436.

18. Stone NM, JL Shelton, BE Haggard and HK Thomforde 2013. Interpretation of water analysis reports for fish culture. Stoneville, Mississippi: Southern Regional Aquaculture Center.

19. Banerjea SM 1967. Water quality and soil condition of fish ponds in some states of India in relation to fish production. Ind. J. Fish., 14(1 \& 2): 115-144.

20. Ahmed KKU, SU Ahmed, GC Haldar, MRA Hossain and T Ahmed 2005. Primary Production and Fish Yield Estimation in the Meghna River System, Bangladesh. Asian Fish. Sci. 18: 95-105.

21. Buttner JK, RW Soderberg, and DE. Terlizzi 1993. An introduction to water chemistry in fresh water aquaculture, NRAC Fact Sheet 170-1993, Northeastern Regional Aquaculture Centre (NRAC).

22. Debjit KM, A Kaviraj and S Saha 2010. Water quality parameters and fish biodiversity indices as measures of ecological degradation: a case study in two floodplain lakes of India. J. Water Res. Protect. 2: 85-92.

23. Shetty A, M Venkateshwarlu and M Muralidharan 2015. Effect of water quality on the composition of fish communities in three coastal rivers of Karnataka, India. Int. J. Aq. Bio. 3(1): 42-51.

(Manuscript receied on 10 August, 2021; accepted on 25 November, 2021) 